\title{
Statin and anemia in chronic kidney disease (CKD): an experimental study
}

\author{
$P N$ Cahyawati $^{1, *}, A A S A$ Aryastuti $^{1}, M B T$ Ariawan $^{1}, N$ Arfian $^{2}$, and Ngatidjan Ngatidjan $^{3}$ \\ ${ }^{1}$ Department of Pharmacology and Pharmacy, Faculty of Medicine and Health Sciences, Universitas Warmadewa Denpasar Bali, \\ Indonesia \\ ${ }^{2}$ Department of Anatomy, Faculty of Medicine, Universitas Gadjah Mada Yogyakarta, Indonesia \\ ${ }^{3}$ Department of Pharmacology and Therapy, Faculty of Medicine, Universitas Gadjah Mada Yogyakarta, Indonesia
}

\begin{abstract}
Anemia is a common feature of chronic kidney disease (CKD). The current management of patients with anemia in CKD is controversial. These make anemia is one of the leading causes poor outcome in CKD patients. Our study focus to assess the effect of statin on hemoglobin level with an experimental model of CKD. We perform the animal model of CKD by subtotal nephrectomy procedure. A total of 20 male swiss was used in these study. All the animal divided into 4 groups: sham group (S), nephrectomy (Nx), simvastatin group $5 \mathrm{mg} / \mathrm{kgBB}$ (SV5), and simvastatin group $10 \mathrm{mg} / \mathrm{kgBB}$ (SV10). Hematological parameters (hemoglobin (Hb), white blood cells (WBC), red blood cell (RBC), hematocrit (HCT), mean corpuscular volume (MCV), mean corpuscular hemoglobin $(\mathrm{MCH})$, mean corpuscular hemoglobin concentration (MCHC)), and serum creatinine are measured at the end of the study. The hemoglobin levels in the Ux group decreased significantly compared with the $\mathrm{S}$ group (11.02 \pm 0.46 vs 14.3 $\pm 0.15, \mathrm{p}<0.0001)$. While in the SV group, statin administration led to an increase in hemoglobin levels compared with the Ux group but not statistically significant (SV5: 13.26 \pm 0.34 ; Sv10: 12.68 \pm 0.26 ). These results suggest that administration of statins in CKD may improve the condition of anemia by an unknown mechanism, while still requiring other treatment options to maximize the effect of therapy.
\end{abstract}

\section{Introduction}

The kidneys have a function to filter the blood, remove the waste products of metabolism and controlling the balance of fluid and electrolytes [1]. Another function of the kidneys are the production of erythropoietin, the molecule that stimulates red blood cell (RBC) production, in response to decreased oxygen levels in the blood. Any disruption of this process has the potential to produce anemia [2]. Anemia is a decrease in red blood cells (RBC) or lowered ability to carry oxygen. It's a common feature in many patients with CKD and is associated with increased risk of cardiovascular disease, morbidity, and mortality [3]. The prevalence of anemia based on the Korean Cohort Study was $45.0 \%$ among 2.198 non-dialysis CKD patients from stage 1 to 5 [4]. In the United States, the prevalence of anemia increased with stage of CKD, from $8.4 \%$ at stage 1 to $53.4 \%$ at stage 5. Anemia was twice as prevalent in people with CKD (15.4\%) as in the general population (7.6\%).[4]

The use of statin in patients with CKD, especially those with an advanced renal disease, remains controversial. These is because that patients are excluded from large clinical trials because of concerns regarding high morbidity and mortality, as well as safety issues of the drugs [5]. Statins inhibit the mevalonate pathway, thereby lowering synthesis of cholesterol. Statins are also reported to have pleiotropic effects such as antioxidation, anti-inflammation, regulation of the immune system and some other.[6] The purpose of these study was to assess the effect of statin on hemoglobin level with an experimental model of CKD based on the pleiotropic effects of statin.

\section{Material and methods}

\subsection{Animals}

All animal procedure was conducted with prior institutional ethical approval that obtained from The Medical and Health Research Ethics Committee Faculty of Medicine, Universitas Gadjah Mada. Twenty healthy Swiss mice, a 3-5 month of age, weighed 30-40 gram, raised in constant temperature environment (temperature $\left(24 \pm 2^{\circ} \mathrm{C}\right)$, humidity $(55 \pm 5 \%)$ and conditions with a 12-hour light-dark cycle), with standardized feeding and unlimited access to drinking water. Simvastatin was purchased from Sigma-Aldrich, Singapore and suspended into a $1 \%$ carboxymethylcellulose (CMC) solution. The serum creatinine reagent was purchased from DiaSys, Germany and hematological parameters obtained using automated hematology analyzer Sysmex, Canada.

\footnotetext{
* Corresponding author: putunitacahyawati@gmail.com
} 


\subsection{Mice Grouping and Treatment}

The 20 Swiss mice were randomly divided into four groups, as follows: blank control group with sham operation $(\mathrm{S})(\mathrm{n}=5)$, experimental control group with subtotal nephrectomy procedure $(\mathrm{Nx})(\mathrm{n}=5)$, low-dose simvastatin group $\left(\mathrm{SV}_{5}\right)(5 \mathrm{mg} / \mathrm{kgBB} ; \mathrm{n}=5)$ and highdose simvastatin group $\left(\mathrm{SV}_{10}\right)(10 \mathrm{mg} / \mathrm{kgBB} ; \mathrm{n}=5)$. On the day of modeling, the mice were weighed and anesthetized via intraperitoneal injection of sodium pentobarbital $0,1 \mathrm{ml} / 10 \mathrm{~g}$ body weight. The mice were placed in the pronation position, and the skin was prepared for the surgery. The operation procedure of subtotal nephrectomy leaves only $1 / 3$ part of the kidney.[7] Blood samples were collected by the retroorbital puncture to measure the hematological parameters $(\mathrm{Hb}, \mathrm{WBC}, \mathrm{RBC}, \mathrm{HCT}, \mathrm{MCV}, \mathrm{MCH}$, $\mathrm{MCHC}$ ) and serum creatinine.

\subsection{Statistical Analysis}

We used the SPSS 21.0 software for data processing. The results were expressed as the mean \pm standard deviation (SD). The data were all normally distributed in each group (Kolmogorov-Smirnov test, $\mathrm{p}>0.05$ ). Statistical analysis between groups was performed using an analysis of variance (one-way ANOVA) followed by Bonferroni test. A p-value less than 0.05 was considered significant.

\section{Results and discussion}

\subsection{Body weight}

Weight gain during the treatment of this study shown in figure 1. Weight loss in $\mathrm{Nx}, \mathrm{SV}_{5}$, and $\mathrm{SV}_{10}$ groups mainly occurs on day 2. This is likely due to kidney removal and acute stress that occurs in mice. This is because stress both acute and chronic can affect eating behavior in animals $[8,9]$.

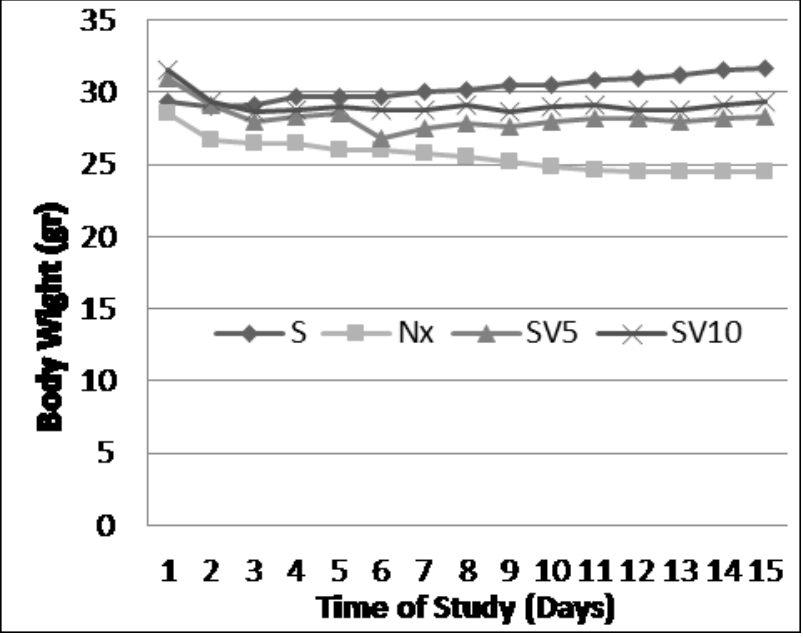

Fig. 1. Weight Gain during The Treatment.

Based on these study, there were significant differences between $\mathrm{S}$ group and Ux group at the end of study $(p<0.005)$. The average of body weight of the mice at the end of treatment in the $\mathrm{S}$ group was an increase compared to the initial treatment $(29.33 \pm 0.84 v s$ $31.67 \pm 2.12, \mathrm{p}<0.026$ ) (Figure 2). In contrast to the $\mathrm{Nx}$ group, where was the weight loss during the treatment period $(28.5 \pm 2.39$ vs $24.5 \pm 6.43)$. In the $\mathrm{SV}_{5}$ and $\mathrm{SV}_{10}$ groups that receiving statins, there was no significant weight change $\left(\mathrm{SV}_{5}: 31.0 \pm 2.45\right.$ vs $28.33 \pm 1.87 ; \mathrm{SV}_{10}$ : $31.5 \pm 1.3$ vs $29.33 \pm 1.3)$ during the treatment.

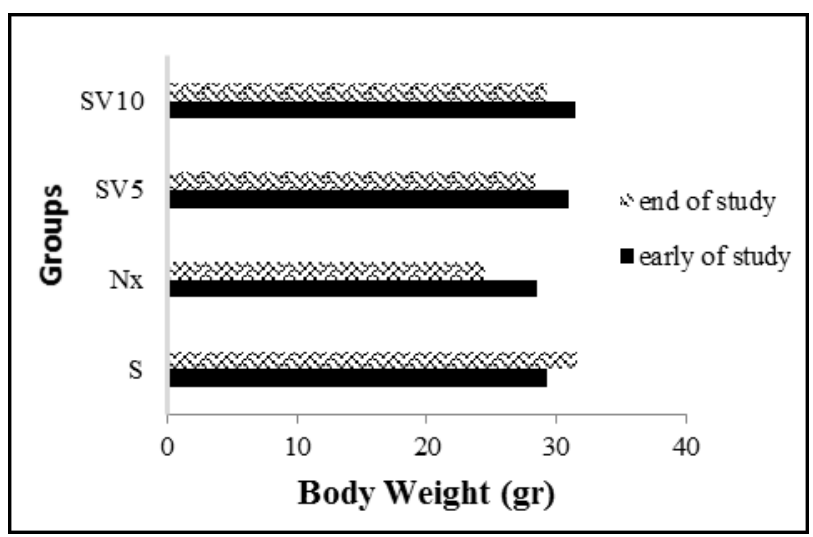

Fig. 2. The Body Weight at Early of Study and The End of Study.

\subsection{Hematological Parameters}

Based on the results of a complete blood count, it was found that the subtotal nephrectomy procedure triggered a significant decrease in hemoglobin levels in the Ux group compared with the $\mathrm{S}$ group $(11.02 \pm 0.46$ vs 14.3 $\pm 0.15, \mathrm{p}<0.0001)$. While in the $\mathrm{SV}$ group, statin administration led to an increase in hemoglobin levels compared to the Ux group but not statistically significant $\left(\mathrm{SV}_{5}: 13.26 \pm 0.34, \mathrm{p}<0.095 ; \mathrm{Sv}_{10}: 12.68 \pm 0.26, \mathrm{p}<1.0\right)$ (Table 1). 
Table 1. Hematological Parameters of mice from the experimental groups.

\begin{tabular}{|c|c|c|c|c|}
\hline \multirow{2}{*}{ Parameter } & \multicolumn{4}{|c|}{ Group } \\
\cline { 2 - 5 } & $\mathbf{S}$ & $\mathbf{N x}$ & $\mathbf{S V}_{\mathbf{5}}$ & $\mathbf{S V}_{\mathbf{1 0}}$ \\
\hline $\mathrm{Hb}(\mathrm{g} / \mathrm{dL})$ & $14.3 \pm 0.15$ & $11.02 \pm 0.46^{\mathrm{b}}$ & $13.26 \pm 0.34^{\mathrm{b}}$ & $12.68 \pm 0.26^{\mathrm{b}}$ \\
\hline $\mathrm{HCT}(\%)$ & $50.86 \pm 1.77$ & $41.68 \pm 7,44^{\mathrm{b}}$ & $45.94 \pm 3.68$ & $44.78 \pm 2.72$ \\
\hline $\mathrm{MCV}(\mathrm{fL})$ & $52.28 \pm 1.04$ & $50.76 \pm 1.18$ & $52.36 \pm 1.21$ & $51.86 \pm 0.91$ \\
\hline $\mathrm{MCH}(\mathrm{pg})$ & $14.74 \pm 0.42$ & $13.96 \pm 0.98$ & $15.12 \pm 0.29^{\mathrm{a}}$ & $14.78 \pm 0.25$ \\
\hline $\mathrm{MCHC}(\mathrm{g} / \mathrm{dL})$ & $28.2 \pm 0.45$ & $27.8 \pm 2.16$ & $29 \pm 1.0$ & $28.6 \pm 0.89$ \\
\hline
\end{tabular}

Values are means $\pm \mathrm{SD}(\mathrm{n}=5)$. Comparisons between groups are made by one way anova, post hoc Bonferroni. $\mathrm{S}$, sham-operated animal; Nx, subtotal nephrectomy; SV, simvastatin-treated.

$$
\mathrm{a}=p<0.05 \text { vs } \mathrm{Nx}, \mathrm{b}=p<0.05 \text { vs } \mathrm{S}
$$

Anemia in CKD is typically normocytic, normochromic, and hypoproliferative [8]. It is most commonly a result of decreased erythropoietin production by the kidneys and/or iron deficiency [9]. These conditions also can occur because in CKD patients have increased iron losses, due to chronic bleeding from uremia-associated platelet dysfunction, frequent phlebotomy, and blood trapping in the dialysis apparatus. The blood loss estimated at $1-3$ g per year in hemodialysis patients.[10] Patients with CKD also may have a functional iron deficiency, which occurs in the setting of induced erythropoiesis during erythropoiesisstimulating agents (ESA) use. These therapies lead to marked increases in the utilization of iron to stimulate the production of new RBC.[11]

We also found that there is a significant difference in level HCT on $\mathrm{S}$ group compared with $\mathrm{Nx}$ group (Figure 3). But no significant difference in level $\mathrm{MCV}, \mathrm{MCH}$, and $\mathrm{MCHV}$ on $\mathrm{S}$ group compared with $\mathrm{Nx}$ group (Figure 4).

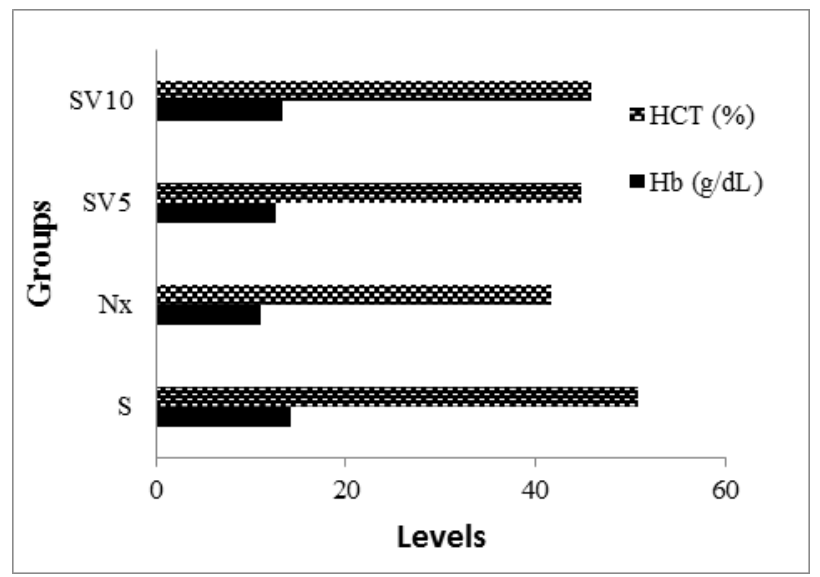

Fig. 3. The HCT and Hb Levels in The Treatment Group.

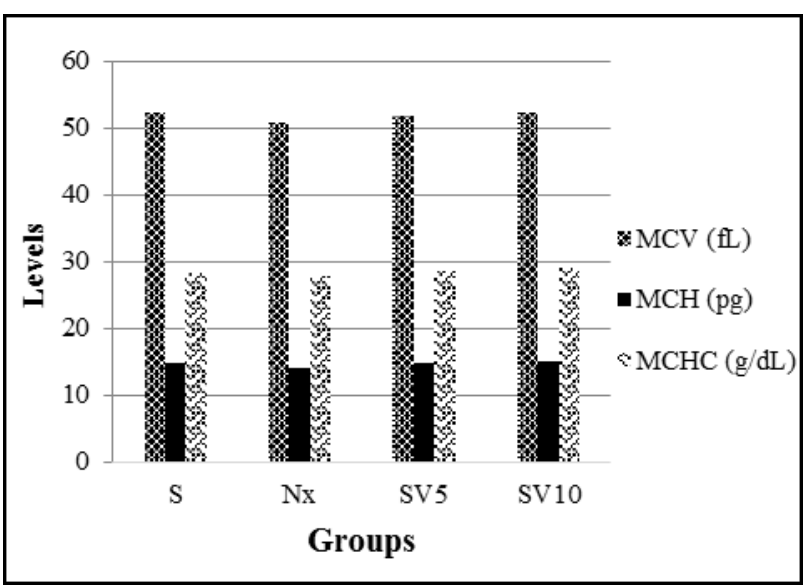

Fig. 4. The MCV, MCH, and MCHC Levels in The Treatment Group.

Statin studies on various models of chronic renal failure have been done in recent years. Statins can lead to improvements in serum creatinine and renal morphology by unknown mechanism. Statin significantly reduced glomerulosclerosis, tubular injury and interstitial fibrosis animal model of CKD [7]. Statin is also reported to be improving the histopathological damage (tubular injury) in salt-loaded Dahl $\mathrm{S}$ rats in a hypertensive model [12]. In rats with unilateral ureteral obstruction (UUO), interstitial fibrosis (IF) was also significantly attenuated with simvastatin treatment, which was confirmed by a decrease in collagen I and fibronectin renal expression [13]. These are probably because statin can down-regulating TGF- $\beta 1$ and T $\beta$ IIR and inhibit the TGF-beta signal pathway [14]. Simvastatin with an under cholesterol-lowering dose can decrease the expression levels of CTGF and $\alpha$-SMA upregulates inhibitors of transforming growth factor-beta signaling, attenuates epithelial-to-mesenchymal transition, and decreases renal fibrosis, by which the progression of the tubulointerstitial fibrosis would be delayed [15], [16]. Event though none of these studies have directly linked the association of statin drugs to anemia in CKD conditions.

In this study, it was found that administration of statins could improve hemoglobin levels in the SV group. This condition can occur probably due to the improvement of renal morphology, especially tubules as a producer of erythropoietin. Erythropoietin that is necessary for erythrocytosis is produced mainly by the proximal tubule of the nephron [3]. Erythropoietin can 
trigger the production of red blood cells, thus improving the condition of the anemia. However, statin alone does not seem to have the maximal effect, so additional therapies are needed to maximize the expected effect of therapy.

\section{Conclusion}

In conclusion, we have shown that subtotal nephrectomy procedure in mice is associated with the occurrence of anemia. Treatment with statins can ameliorate the anemic condition but not statistically significant. The additional therapies are needed to maximize the expected effect of therapy.

\section{References}

1. M E Stauffer, T Fan. PLoS One 9, 1. (2014)

2. R E Smith, A M J Manag Care. 16. (2010)

3. F Kutuby, S Wang, C Desai and E V Lerma. Disease-a-Month 61, 10. (2015)

4. S R Ryu, S K Park, J Y Jung, Y H Kim, Y K Oh, T H Yoo and S Sung. J Korean Med Sci 32, 2. (2017)

5. C M Chung, M S Lin, J T Hsu, J F Hsiao, S T Chang, K L Pan, C L Lin and Y S Lin. J Clin Lipidol 11, 2. (2017)

6. H Shahbazian, A Atrian, L Yazdanpanah, G Lashkarara, M A Zafar. Jundishapur J Nat Pharm Prod 10, 1. (2015)

7. P N Cahyawati, Ngatidjan, D C R Sari, M M Romi and N Arfian. Int J Pharm Pharm Sci 9, 5. (2017)

8. J Maniam, M J Morris. Neuropharmacology 63. (2012)

9. $\quad$ S J Torres, C A Nowson. Nutrition 23 p11-12. (2007)

10. J L Babitt, H Y Lin. J Am Soc Nephrol. 23, 10. (2012)

11. J Bahrainwala, J S Berns. Semin Nephrol. 36, 2. (2016)

12. M Kido, K Ando, S Oba and T Fujita. Hypertens Res 28, 12. (2005)

13. J M Vieira, E Mantovani, L T Rodrigues, H Delle, I L Noronha, C K Fujihara and R Zatz. Nephrol Dial Transplant 20, 8. (2005)

14. Z X Chen, M X Lei, L F Zhu and J Zhang. J Cent South Univ 30, 5. (2005)

15. A R Chade, X Y Zhu, J P Grande, J D Krier, A Lerman and L O Lerman. J Hypertens 26, 8. (2008)

16. F L Lin, $\mathrm{H} C$ Shen, B Zhu and K Q. Zhejiang Da Xue Xue Bao Yi Xue Ban 39, 5. (2010) 